\title{
Utilização da terapia fotodinâmica antimicrobiana e fototerapia a laser no tratamento da dermatite interdigital infecciosa ovina
}

\author{
Use of photodynamic antimicrobial therapy and laser therapy in the treatment \\ of ovine infectious dermatitis
}

\author{
Fernando Alzamora Filho ${ }^{1 *}$, Miram Pinto Cavalcante ${ }^{2}$, Nilza Marcia Alves Rocha ${ }^{1}$, Vinícius de Oliveira Costa \\ Souza ${ }^{1}$, Thiago Santos Ribeiro ${ }^{1}$, Thalita Marques de Brito ${ }^{3}$, Luiz Gustavo Ribeiro Reis ${ }^{3}$ \\ ${ }^{1}$ Universidade Estadual de Santa Cruz (UESC), Ithéus, BA, Brasil \\ ${ }^{2}$ Médica Veterinária, Ithéus, BA, Brasil \\ ${ }^{3}$ Hospital Veterinário - Clínica Médica de Grandes Animais, Universidade Estadual de Santa Cruz (UESC), \\ Ithéus, BA, Brasil
}

\section{Resumo}

A dermatite interdigital infecciosa ovina é uma doença cosmopolita e ocasiona perdas econômicas na produção animal. 0 presente trabalho teve como objetivo relatar as alterações clínicas e o uso de fototerapias com laser em um caso de dermatite interdigital infecciosa em um ovino, proveniente de Itabuna, Bahia. No exame físico, o paciente apresentou claudicação, não apoio do casco no solo, unhas com crescimento irregular e deslocamento da sola e muralha, com exposição do cório subjacente. Instituiu-se tratamento baseado em limpeza diária das lesões, apara terapêutica, e associação da terapia fotodinâmica antimicrobiana e laserterapia de baixa potência com laser vermelho nas lesões podais. Os parâmetros dosimétricos, energia (J) e fluência $\left(\mathrm{J} / \mathrm{cm}^{2}\right)$ variaram de acordo com as características e extensão das lesões dos dígitos. Ao término do tratamento, houve cicatrização completa das lesões podais e ausência de claudicação. Conclui-se que a associação da terapia fotodinâmica antimicrobiana e da laserterapia com laser vermelho foi eficiente no tratamento, sendo uma alternativa promissora ao tratamento convencional.

Palavras-chave: Dichelobacter nodosus. Foot rot. Fotobiomodulação. Terapia fotodinâmica.

\begin{abstract}
Ovine infectious dermatitis or foot rot is a cosmopolitan disease and causes losses in animal husbandry. The objective of this study was to report the clinical features of a case of foot rot in a sheep from Itabuna, Bahia and treatment of this case using the diode laser. Physical examination revealed that the patient exhibited claudication, did not
\end{abstract}


place the hoof on the floor, had nails with irregular growth on the hoof, and showed displacement of the sole and wall with the corium exposed. The treatment consisted of daily cleaning of the lesions, foot trimming, and photodynamic antimicrobial therapy and laser therapy with a red laser in the foot lesions. The dosimetric parameters, energy (J) and fluence $\left(\mathrm{J} / \mathrm{cm}^{2}\right)$, varied according to characteristics and extent of the claw lesions. At the end of the treatment, a complete resolution of the foot lesions and absence of claudication were noted. Therefore, it can be concluded that the combination of photodynamic therapy and laser therapy with the red laser might be an effective treatment for foot rot, and serves as a promising alternative to conventional treatments.

Keywords: Dichelobacter nodosus. Foot rot. Laser therapy. Photodynamic therapy.

\section{Introdução}

A dermatite infecciosa ovina ou foot rot é uma doença cosmopolita que ocasiona prejuízos econômicos significativos na ovinocultura, como redução da produtividade, problemas reprodutivos, gastos com tratamentos e descarte involuntário (Strobel et al., 2014; Silveira et al., 2016). 0 agente causal é a associação do Dichelobacter nodosus com o Fusobacterium necrophorum, podendo estar presentes espiroquetas, ocasionando lesões nos tecidos epidérmicos do espaço interdigital e córneo do casco (Clifton e Green, 2016). As alterações clínicas se iniciam com uma dermatite da pele interdigital, progredindo para separação da sola e da muralha do casco, com exposição do cório subjacente (Winter, 2008; Silveira et al., 2016). 0 tratamento consiste no isolamento, casqueamento, antibioticoterapia tópica e sistêmica, além do uso de pedilúvio (Winter, 2008; Strobel et al., 2014).

A terapia fotodinâmica antimicrobiana (TFDa) é uma alternativa terapêutica aos tratamentos convencionais para lesões infectadas localizadas, restringindo o uso de antibióticos e impedindo o desenvolvimento de resistência bacteriana (Bagnato et al., 2017). Essa terapia envolve o uso de um fotosensibilizador, luz de comprimento de onda específico e oxigênio molecular, que iniciará uma reação química para a formação de espécies reativas de oxigênio e produção de oxigênio singleto, permitindo destruir microrganismos pelas alterações de estruturas fundamentais para sua sobrevivência (Chavantes, 2009; Bagnato et al., 2017). A laserterapia de baixa potência (LBP) pode ser usada isoladamente ou associada a outras terapias, e os efeitos no tecido biológico lesionado são analgesia, diminuição do processo inflamatório, redução do edema, restauração tecidual e estimulação da microcirculação local (Chavantes, 2009; Andrade et al., 2014).

O objetivo desse trabalho foi relatar as alterações clínicas e os efeitos do uso da TFDa e da LBP como alternativa de tratamento das lesões causadas pela dermatite infecciosa ovina.

\section{Relato de caso}

Descreve-se um caso de dermatite interdigital infecciosa em um ovino, SRD, 6 meses de idade, oriundo do município de Itabuna, Bahia, que foi atendido no Hospital Veterinário da Universidade Estadual de Santa Cruz em função de lesões podais nos membros torácicos. 0 paciente apresentava claudicação grave e não apoiava o membro torácico direito (MTD) no solo. Foram observados dígitos com crescimento excessivo do estojo córneo, dermatite no espaço interdigital, separação da muralha abaxial e da sola, com exposição do cório e presença de exsudato acinzentado de odor pútrido. Segundo o sistema de escore para classificação clínica da dermatite interdigital infecciosa (Ware e Kluver, 2014), o casco do MTD era escore 4 e o casco do membro torácico esquerdo (MTE) era escore 3.0 diagnóstico da lesão podal foi baseado na anamnese e em sinais clínicos e bacteriológicos, através da observação do $D$. nodosus em esfregaços corados pela técnica de Gram.

0 tratamento inicial foi a apara terapêutica dos cascos e limpeza das lesões com solução fisiológica 0,9\% (Figura 1). As áreas das lesões dos dígitos lateral e medial do MTD foram de $4,5 \mathrm{~cm}^{2} \mathrm{e}$ $4,0 \mathrm{~cm}^{2}$, e para o MTE foram de $14 \mathrm{~cm}^{2}$ e $2,5 \mathrm{~cm}^{2}$, respectivamente. Foi instituído tratamento único com TFDa, no qual as lesões podais foram irradiadas com laser de diodo com $0,1 \mathrm{~W}$ de potência, emissão 
contínua, área do spot de $0,028 \mathrm{~cm}^{2}$ e irradiância de $3,5 \mathrm{~W} / \mathrm{cm}^{2}$. Inicialmente, foi aplicada sobre a lesão gaze embebida com $5 \mathrm{~mL}$ de solução aquosa de azul de metileno $(300 \mu \mathrm{M})$, com tempo de pré-irradiação de 5 minutos e irradiada com laser vermelho $(\lambda=660 \mathrm{~nm})$, energia de 9J por ponto de aplicação, fluência/ponto de $321 \mathrm{~J} / \mathrm{cm}^{2}$ e tempo de exposição/ ponto de 90 segundos. 0 número de pontos empregados para irradiar as lesões, com intervalo de $1 \mathrm{~cm}$ entre eles, foi de dois para os dígitos lateral e medial do MTD e de quatro e um para os dígitos lateral e medial do MTE, respectivamente. Também foram realizadas duas sessões de LBP com comprimento de onda de $660 \mathrm{~nm}$, energia de 1J por ponto, fluência/ponto de $35,7 \mathrm{~J} / \mathrm{cm}^{2}$, tempo de exposição/ponto de 10 segundos e intervalos de 24 e 96 horas após a TFDa. Os números de pontos para irradiar as lesões podais foram três para o MTD e quatro para o MTE. Os cascos foram protegidos por bandagem e diariamente as lesões foram avaliadas clinicamente até sua cicatrização completa.
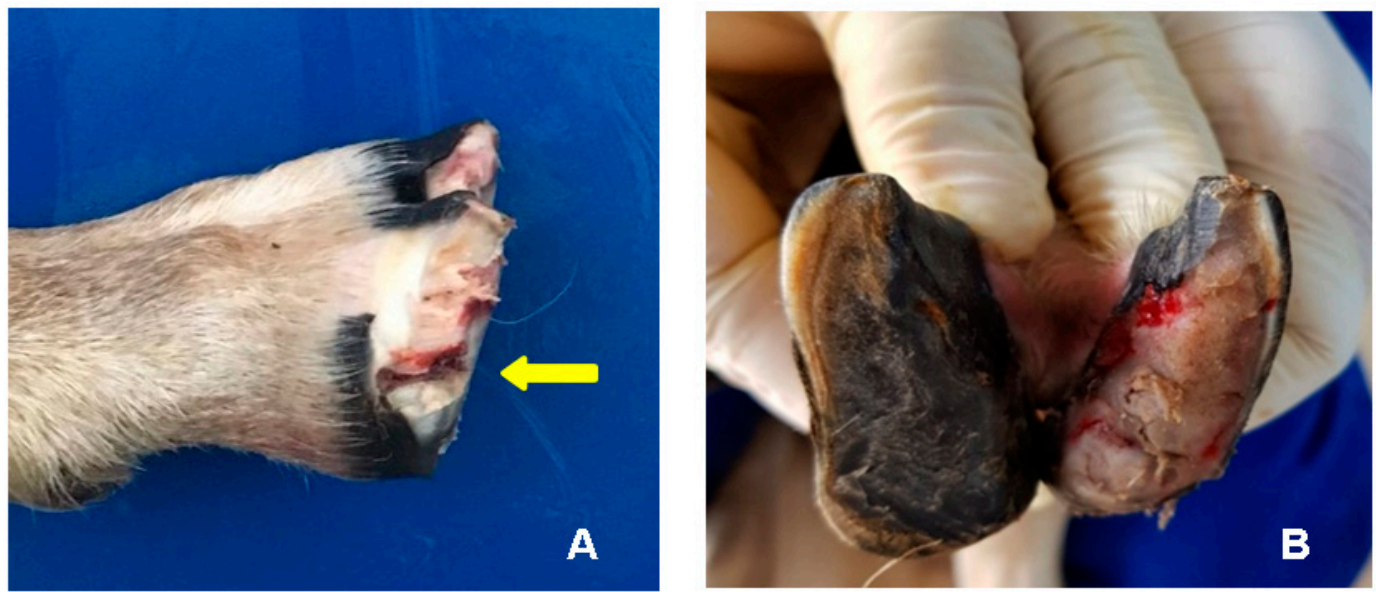

Figura 1 - Apara terapêutica dos cascos. A: retirada da muralha abaxial e fissura vertical (seta); unha lateral do membro torácico direito. B: retirada das estruturas necrosadas da sola; unha medial do membro torácico esquerdo.

\section{Resultados e discussão}

A dermatite infecciosa ovina é causa comum de claudicação em ovinos e o tratamento preconizado é composto de casqueamento, pedilúvio e antibioticoterapia (Strobel et al., 2014; Silveira et al., 2016). Neste relato, preconizou-se a apara terapêutica associada ao uso da TFDa, por provocar a morte seletiva de vários microrganismos sem o uso de antibióticos (Chavantes, 2009; Gomes et al., 2016), e da LBP, devido aos efeitos de biomodulação e bioestimulação consistentes com a homeostase celular (Chavantes, 2009; Andrade et al., 2014). Após o término da TFDa, o paciente apresentou uma redução da intensidade da dor, apoiando parcialmente o casco do MTD no solo. Vinte e quatro horas após o tratamento, a dermatite interdigital observada nos cascos do MTD e MTE apresentou redução da inflamação e ausência de secreção. As lesões no estojo córneo dos cascos apresentaram uma fina camada de tecido epidérmico queratinizado. Após a primeira sessão de LBP, observou-se aumento da ingestão de alimento e ausência de inflamação nos cascos.

Na segunda sessão de LBP, no quinto dia de internamento, era evidente a reepitelização do espaço interdigital, muralha e sola (Figura 2A) e o efeito analgésico sobre as lesões podais, através da ausência de claudicação do paciente e do teste de pinçamento do casco. Esses resultados são ocasionados pelo efeito fotoquímico da terapia laser, restabelecendo a homeostase energética da célula, inibição de mediadores inflamatórios, analgesia, proliferação de células endoteliais e de 
queratinócito, aumento da síntese e deposição de colágeno e neoanginogênese (Chavantes, 2009; Andrade et al., 2014). Os resultados do presente estudo corroboram os de Sellera et al. (2017), que trataram dez lesões de dermatite digital em vacas leiteiras com duas sessões de TFDa e observaram completa cicatrização das lesões aos 28 dias. Gomes et al. (2016) também relataram que a TFDa foi eficiente na redução da claudicação em bovinos com lesões digitais.
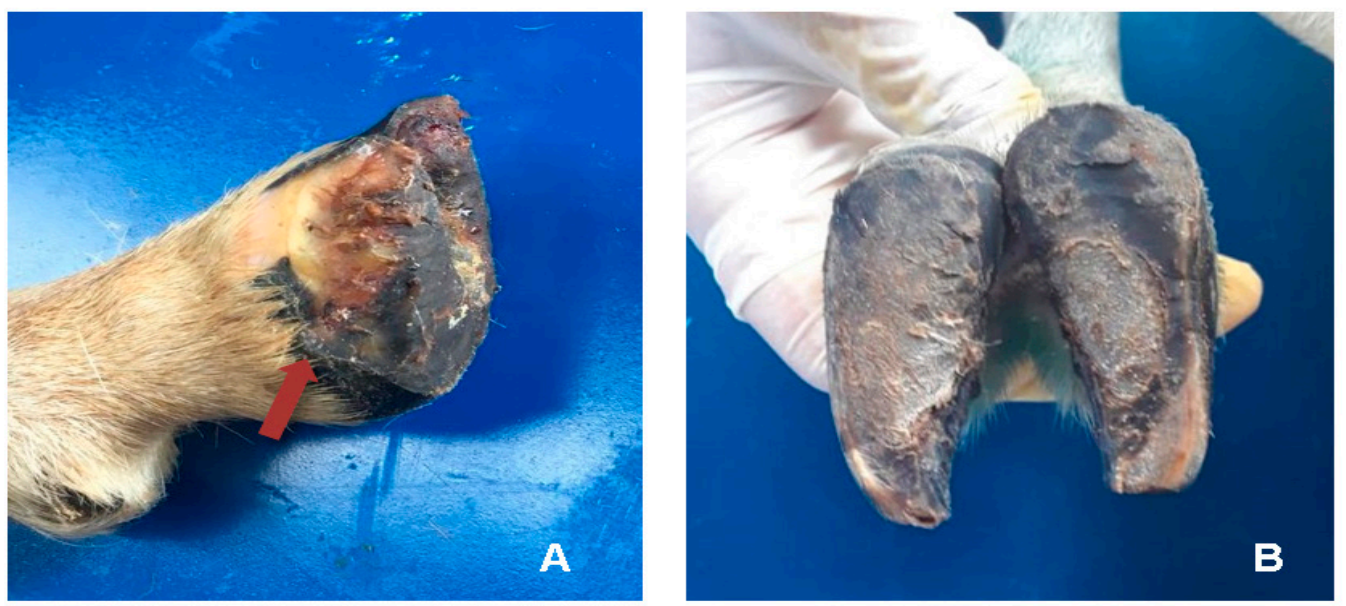

Figura 2 - A: presença de tecido epidérmico queratinizado e redução da fissura (seta); dia 5; membro torácico direito. B: recuperação clínica das lesões podais; dia 11; membro torácico esquerdo.

Strobel et al. (2014) avaliaram a eficácia da aplicacação de $6 \mathrm{mg} / \mathrm{kg}$ de gamitromicina no tratamento da pododermatite ovina em comparação a $20 \mathrm{mg} / \mathrm{kg}$ de oxitretraciclina. 0 estudo relatou uma redução da claudicação em ambos os tratamentos nas dez fazendas participantes, com uma taxa de cura aos 21 dias de $79,3 \%$ para oxitetraciclina e de $93,7 \%$ para gamitromicina. No presente trabalho, observouse ausência de claudicação no quinto dia, aumento da ingestão de matéria seca e cicatrização das lesões podais com 11 dias de internamento (Figura 2B).

\section{Conclusão}

0 tratamento com terapia fotodinâmica antimicrobiana e laserterapia foi eficiente na recuperação das lesões podais do ovino, sem o uso de antibióticos, e na melhora da condição clínica do paciente, promovendo bem-estar animal. 0 ovino apresentou redução da claudicação e das lesões podais em um período curto de tempo, sendo uma promissora terapia complementar. Por ser o primeiro relato sobre utilização da fototerapia laser em dermatite infecciosa ovina, são necessários mais estudos para estabelecer a dosimetria e frequência das sessões e confirmar os efeitos observados nesse relato.

\section{Referências}

Anderson Andrade FSSD, Clark RMO, Ferreira ML. Efeitos da laserterapia de baixa potência na cicatrização de feridas cutâneas. Rev Col Bras Cir. 2014;41(2):129-33.

Bagnato VS, Kurachi C, Blanco KC, Inada NM. Antimicrobial Photodynamic Therapy. In: Hamblin MR, Sousa MVP, Agrawal T (EE.). Handbook of LowLevel Laser Therapy. Singapore: Pan Stanford; 2017. p. 273-83.

Chavantes MC. Laser em bio-medicina: princípios e prática. São Paulo: Atheneu; 2009. 281 p. 
Clifton R, Green L. Pathogenesis of ovine footrot disease: a complex picture. Vet Rec. 2016;179(9):225-7.

Gomes JPFS, Ramos RR, Frias DFR, Marques VB, Kozusny-Andreani DI, Fernandes AU. Evidências do efeito da terapia fotodinâmica sobre infecções podais em vacas leiteiras no município de Fernandópolis, São Paulo, Brasil. Rev Bras Med Vet. 2016; 38(3):25764.

Sellera FP, Gargano RG, Barbosa BS, Anjos C, Lopes LA, Ollhoff RD, et al. Antimicrobial photodynamic therapy for digital dermatitis. 19th International Symposium and 11th Conference Lameness in Ruminants; 7-9 set 2017; Munique, Alemanha. 2017. p. 66-7.
Silveira CS, Damboriarena PA, Morais RM, Trost ME, Pozzobon R, Anjos BL. Lesões podais em ovinos da Mesorregião Sudoeste do Rio Grande do Sul. Pesq Vet Bras. 2016;36(10):971-8.

Strobel H, Lauseker M, Forbes AB. Targeted antibiotic treatment of lame sheep with footrot using either oxytetracycline or gamithromycin. Vet Rec. 2014;174(2):46.

Ware JW, Kluver P. Footrot manual for contractors. Australia: Livestock Biosecurity Networks; 2014 [acesso 4 jun 2018]. Disponível em: https://tinyurl.com/y9vf8k5j.

Winter AC. Lameness in sheep. Small Rum Res. 2008;76(1-2):149-53. 